\title{
O DESAFIO DE QUALIFICAR PROFESSORES PARA A DIVERSIDADE: A REALIDADE DO ESTADO DO AMAPÁ
}

\section{The challenge of qualifying teachers for diversity: the reality of the state of Amapá}

\author{
Efigênia das Neves B. Rodrigues ${ }^{1}$ \\ Elivaldo Serrão Custódio ${ }^{2}$ \\ Eugénia da Luz Silva Foster ${ }^{3}$ \\ UFAP - Macapá/ Brasil
}

\begin{abstract}
RESUMO: O presente trabalho é o resultado de um estudo sobre formação de professores da rede pública de ensino do estado do Amapá. O documento propõe uma reflexão acerca da necessidade de se repensar a prática educativa, considerando a Lei Federal ${ }^{\circ} 10.639 / 2003$ e Lei Estadual $n^{\circ}$ 1.196/2008 no âmbito escolar. Trata-se do resultado de um estudo exploratório de natureza qualitativa que adotou a pesquisa bibliográfica, a análise documental e a entrevista como forma de investigação. O texto é resultado de pesquisas do Grupo de Estudos e Pesquisas sobre Educação, Relações Étnico-Raciais e Interculturais, cadastrado no CNPq que tendo como objetivo identificar e analisar as concepções sobre as questões raciais no Brasil, em especial no Amapá, que sustentam as práticas pedagógicas e os discursos de professores, no desdobramento do currículo escolar, bem como avaliar suas possibilidades de enfrentamento ao racismo.
\end{abstract}

Palavras-chave: Ensino. Diversidade. Formação de professores. Amapá

ABSTRACT: The present work is the result of a study about teacher training in the public school system of the state of Amapá. The document proposes a reflection on the need to rethink the educational practice, considering Federal Law n. 10.639 / 2003 and State Law n. 1,196 / 2008 in the school context. This is the result of an exploratory study of a qualitative nature that adopted the bibliographical research, the documentary analysis and the interview as a form of investigation. The text is the result of research conducted by the Group of Studies and Research on Education, Ethnic-Racial and Intercultural Relations, registered with $\mathrm{CNPq}$, which aims to identify and analyze the conceptions about racial issues in Brazil, especially in Amapá, which support practices pedagogical and teacher discourses, in the unfolding of the school curriculum, as well as to evaluate their possibilities of facing racism.

Keywords: Education. Diversity. Teacher training. Amapá.

\footnotetext{
${ }^{1}$ Mestre em Desenvolvimento Regional pela Universidade Federal do Amapá (UNIFAP), Universidade Meta/Amapá. E-mail: efigenia_nb@yahoo.com.br.

${ }^{2}$ Pós-Doutor em Educação pela Universidade Federal do Amapá (UNIFAP). Doutor em Teologia pela Faculdades EST, em São Leopoldo/RS. Professor no Mestrado em Educação (PPGED/UNIFAP), coordenador e do Curso de Pedagogia da Faculdade Madre Tereza em Santana/Amapá/Brasil. E-mail: elivaldo.pa@hotmail.com

${ }^{3}$ Professora Associada IV da Universidade Federal do Amapá (UNIFAP). Doutora em Educação pela Universidade Federal de Fluminense (UFF). Pós-Doutora em Educação pela Universidade Estadual do Rio de Janeiro (UERJ). E-mail: eugenia.luz@hotmail.com
} 


\section{Conversas introdutórias}

A formação docente nos dias atuais supõe uma constante reflexão sobre as práticas docentes diante das incertezas e dilemas que se apresentam na contemporaneidade. Essas questões não tem sido tarefa fácil para uma parcela considerável de professores/as, pois muitos deles/as não têm visualizado em suas formações sejam iniciais ou continuadas, conhecimentos teóricos e práticos que possam qualificá-los para superar os problemas que surgem na sociedade.

Isso porque a temática formação de professores/as sempre esteve pautada em princípios e modelos fundamentados no sistema econômico. E nos últimos anos o grau de complexidade tem aumentado, pois à medida que as relações entre educação, cultura, cotidiano escolar, processos educativos e a ação do/a professor/a em sala de aula se apresentam de forma complexa, exigem dos cursos de licenciatura e mais especificamente do Curso de Pedagogia possíveis respostas e/ou alternativas para a formação dos/as docentes mais reflexivos, com uma consciência mais sensível sobre as questões sociais, ideológicas e culturais (GOMES; SILVA, 2011).

Assim é preciso que se observe que "formar-se professor dar-se-á num processo contínuo, seja nas fases distintas do ponto de vista curricular realizadas durante a formação inicial, seja na progressiva educação, proporcionada pelo exercício da profissão" (GOMES; SILVA, 2011, p. 12).

Ao analisar a questão ora mencionada, compreende-se que esse processo formativo perpassa por princípios éticos, pedagógicos e didáticos independem do grau de formação desse profissional. Dessa forma, torna-se necessário manter uma constante relação entre a formação inicial e continuada. Pois, os saberes construídos na formação inicial servem de ancoragem por oferecer referências importantes durante o processo formativo permitindo aos/as professores/as criarem e recriarem suas práticas nos primeiros anos de docência. Segundo (NÓVOA, 1991, p. 23):

A formação não se constrói por acumulação (de cursos, conhecimentos ou técnicas), mas sim através de um trabalho de reflexividade críticas sobre as práticas e de (re) construção permanente de uma identidade pessoal. Por isso e tão importante investir na pessoa e dar um estatuto ao saber da experiência. 
Essas reflexões nos levam a pressupor que os conhecimentos construídos na formação devam ser contextualizados e significativos com a finalidade de manter uma conexão entre o saber acadêmico e o sociocultural, pensando na formação do/a professor/a enquanto pessoa, profissional e acima de tudo cidadão reflexivo. Ao articular essas questões a formação, nestes termos, tornar-se coerente propiciar ao educador subsídios científicos, compreensão do contexto social e cultural, para entender e mediar questões de aprendizagem e de ensino.

O que se tem observado ao longo do tempo é que a realidade da educação no Brasil não esta descolada do contexto mundial e vem sofrendo significativas mudanças ocasionadas pelo processo de transformações do capital e, consequentemente, das relações de trabalho. Essas mudanças têm levados governos nas três esferas a repensarem o significado de qualidade da educação, bem como reavaliar seus conceitos com intuito de atender as exigências econômicas, que cada vez mais exige pessoas capazes de responder aos desafios da nova ordem do capital internacional.

$\mathrm{Na}$ América Latina, assim como no Brasil, as reformas econômicas de ajuste estrutural se baseiam no Consenso de Washington. ${ }^{1} \mathrm{O}$ consenso recomenda a abertura da economia, o corte dos gastos sociais, flexibilização dos direitos trabalhistas, privatização de estatais e o controle do déficit fiscal. Esse conjunto de medidas representa um retrocesso para a sociedade, pois o estado mínimo que se instalou tem contribuído para o aumento do desemprego em grande escala, corte nas verbas para a educação, assim como para outras áreas tem ocasionado "uma ditadura da classe dominante sobre a classe trabalhadora, onde os direitos sociais foram banidos ou transformados em mercadorias" (DEL PINO, 2002, p. 42).

Gentili (1996) salienta que o neoliberalismo, além, de transformar a realidade econômica, política, e social dos países, inculca nas pessoas, através de processos ideológicos, a aceitá-lo como única forma para solução dos problemas ocasionados pela crise. ${ }^{1}$ Consenso de Washington - refere-se, em última instância, a um conjunto de instituições financeiras
internacionais como o Banco Mundial, e o Banco Interamericano de Desenvolvimento (BID). 
É nesse cenário econômico que se observa as políticas educacionais do Brasil vêm sendo orientadas pelos princípios do Banco Mundial (BM), seguindo os acordos firmados na Conferência de Educação para Todos. ${ }^{2}$ Pautado nestes acordos, o BM vem fazendo ao longo dos anos, investimentos na educação básica e o propósito desses investimentos é melhorar o capital humano no intuito de reduzir o alto índice de pobreza.

Observa-se que o grande interesse do BM em investir na educação brasileira, perpassa pela preocupação em qualificar os indivíduos para atenderem as necessidades mercadológicas, impulsionadas pelo capital internacional e a escola é a instituição que promoverá esses ajustes. Sacristán (1996, p. 153) introduz um ponto importante quando afirma:

O espírito que orienta a educação pública, herdado da Revolução Francesa, é o de ser um poder para aperfeiçoar o corpo social e servir ao seu progresso, além de servir à liberdade individual; isto é, ela está animada de propósito coletivo.

Partindo desse contexto, pode-se afirmar que a educação é uma forma de garantir o direito de todos, principalmente dos jovens trabalhadores, entretanto, uma educação pautada nos ideais do capitalismo, pouco ou nada contribui para o desempenho da transmissão e reinvenção da cultura além do estímulo à construção da cidadania.

A Conferência Mundial de Educação para Todos (1990) em seu artigo $3^{\circ}$ inciso $4^{\circ}$, diz que universalizar o acesso à educação e promover a equidade requer:

\footnotetext{
Um compromisso efetivo para superar as disparidades educacionais deve ser assumido. Os grupos excluídos - os pobres: os meninos e meninas de rua ou trabalhadores; as populações das periferias urbanas e zonas rurais os nómades e os trabalhadores migrantes; os povos indígenas; as minorias étnicas, raciais e linguísticas: os refugiados; os deslocados pela guerra; e os povos submetidos a um regime de ocupação - não devem sofrer qualquer tipo de discriminação no acesso às oportunidades educacionais (Grifos nossos).
}

\footnotetext{
${ }^{2}$ A Conferência Mundial de Educação para Todos foi realizada em março de 1990 em Jomtien (Tailândia) com o apoio do BM e também de outras instituições internacionais como a UNESCO, a Fundação das Nações Unidas para a Infância (UNICEF) e o Programa das Nações Unidas para o Desenvolvimento (PNUD).
} 
Observa-se no artigo $3^{\circ}$ da Conferência de Educação para Todos, que uma das formas para se alcançar qualidade na educação dos grupos minoritários, incluindo os grupos étnicos raciais é investindo na formação do/a professor/a. No Brasil, na década de 1990, essas iniciativas surgiram em forma de programas como reciclagem, treinamento, capacitação dentre outras questões, visava uma qualificação profissional, direcionada à atuação dos/as professores/as no chão da escola.

$\mathrm{Na}$ percepção do $\mathrm{BM}$, esses profissionais deveriam está instrumentalizados para atuarem nas escolas, com o intuito de melhorar a qualidade da educação. Como se observa no $\operatorname{artigo} 4^{\circ}$ que trata da concentração e a atenção na aprendizagem, o inciso $1^{\circ}$ define:

\footnotetext{
A tradução das oportunidades ampliadas de educação em desenvolvimento efetivo - para o indivíduo ou para a sociedade - dependerá, em última instância, de, em razão dessas mesmas oportunidades, as pessoas aprenderem de fato, ou seja, apreenderem conhecimentos úteis, habilidades de raciocínio, aptidões e valores (UNESCO, 1990).
}

Para se alcançar tais objetivos, se faz necessário pensar em uma formação pautada nos conceitos de desenvolvimento profissional. Para Garcia (1995), nesse conceito estão implícitos os princípios que proporcionará o crescimento e a continuidade do fazer pedagógico do/a professor/a. Este conceito pressupõe a valorização de elementos importantes que se fazem necessário para romper com o caráter individualista dos processos de formação, além de orientar as mudanças no trabalho do professor na sociedade plural.

O presente trabalho é o resultado de um estudo sobre formação de professores/as da rede pública de ensino do Estado do Amapá. O documento propõe uma reflexão acerca da necessidade de se repensar a prática educativa, considerando a Lei Federal $n^{\circ}$ 10.639/2003 e Lei Estadual $n^{\circ} 1.196 / 2008$ no âmbito escolar. O texto analise ainda o Curso de Especialização no Ensino de História e da Cultura Afro-Brasileira, promovido por uma instituição privada de ensino superior no Estado, denominada Faculdade Atual, através de convênio firmado com a Secretaria de Estado de Educação do Amapá (SEED) no ano de 2013. 
Trata-se do resultado de um estudo exploratório de natureza qualitativa que adotou a pesquisa bibliográfica, a análise documental e a entrevista como forma de investigação. $O$ texto é resultado de pesquisas do Grupo de Estudos e Pesquisas sobre Educação, Relações Étnico-Raciais e Interculturais, cadastrado no CNPq que tendo como objetivo identificar e analisar as concepções sobre as questões raciais no Brasil, em especial no Amapá, que sustentam as práticas pedagógicas e os discursos de professores/as, no desdobramento do currículo escolar, bem como, avaliar suas possibilidades de enfrentamento ao racismo.

Algunas considerações sobre a organização da sistematização educacional amapaense: de 1944 a 2014

Após a desagregação do Território do Amapá do Estado do Pará, a cidade de Macapá se transformou em Território, eram muitos desafios para organizar um território recémcriado, implantar um sistema educacional que era praticamente inexistente, convencer os moradores que viviam de forma humilde e acostumados à labuta diária da roça, a vida simples, transformar o modo de vida desses caboclos amazônidas tornou-se um grande desafio ao novo governador.

De acordo com Lobato (2009) com o compromisso de melhorar o nível de escolaridade no novo Território, o governador da época, Janary Nunes viu na escola essa possibilidade e incumbiu aos/as professores/as essa responsabilidade. Esperava-se dos/as professores/as e da escola um trabalho que contribuísse com a mudança na forma de pensar das pessoas, somente dessa forma, o Amapá entraria na rota de desenvolvimento econômico.

Para alcançar os objetivos traçados, Janary Nunes toma medidas urgentes para melhorar a educação no Território, expandiu o número de grupos escolares passando para vinte e três (23), bem como estipulou o novo horário de funcionamento das escolas para três (03) turnos, ampliando ainda o número de professores/as para trinta e três (33), instalando a Cooperativa Agrícola Escolar ${ }^{5}$. Cria ainda o curso ginasial, fazendo-o funcionar num prédio que no inicio chamou-se Ginásio Amapaense e posteriormente, Escola Barão do Rio Branco, além da formação de professores/as através de cursos de férias oferecidos no período de recesso escolar ${ }^{3}$.

${ }^{3}$ O primeiro destes cursos foi realizado na segunda quinzena de junho de 1944, na cidade de Macapá com a 
Esses cursos tinham por objetivos repassar aos docentes novas técnicas de ensino, bem como a difusão das ideias e valores do sistema de governo que estava em vigor na época. Nesses cursos, o governador costumava proferir suas palestras como forma de ensinar aos docentes como deveriam agir em sala de aula com seus alunos na visão do governo o trabalho deveria ter disciplina com a finalidade de melhorar o nível de escolaridade da população amapaense.

De acordo com Lobato (2009, p. 128) ao assumir o governo, Janary Nunes percebeu que a população amapaense era composta por pessoas analfabetas, pois através do relatório das atividades do governo, a forma de registro nas folhas de pontos era a "datiloscopia do dedo polegar".

Segundo Santos (1998), a população amapaense era constituída por vinte e seis mil (26.000) habitantes para ser atendida por sete (07) escolas assim distribuídas: duas em Macapá, uma no Amapá, uma na Vila de Mazagão Velho, uma no Rio Pedreira e a última no povoado de Tarumã em Oiapoque. Segundo ainda o autor, nenhuma escola de caráter privado. Essas escolas atendiam duzentos e noventa e cinco (295) alunos/as e eram totalmente desprovidas de recursos materiais, financeiros e estrutura física. O quadro docente era formado por dez (10) professores/as ativos, dos quais cinco (05) eram leigos e cinco (05) normalistas e o mais grave de tudo isso, estes profissionais não eram qualificados para atuarem em sala de aula.

Na concepção de Janary Nunes, o novo homem amapaense deveria ser ambicioso, ativo, interessado no lucro visando o enaltecimento da economia nacional e local, para tanto, era necessário uma nova forma de educar e viver. Janary Nunes entendia que a forma como gerenciava a educação era correta e reprimia qualquer manifestação contrária à sua gestão. $\mathrm{O}$ ensino por sua vez, restringia-se à exaltação e à valorização do seu governo, considerando-se antipatriota e contrária ao desenvolvimento da região qualquer contestação da autoridade governamental. Neste sentido, 
O ensino nas terras amapaenses, apesar de oficialmente instituído há quase um século e meio, ensinava somente até o terceiro ano do primário, através de um currículo anacrônico, com os alunos aprendendo tão somente elementares conhecimentos de leitura, escrita e matemática, o que era muito pouco para uma sociedade em estruturação e que precisava de pessoas capacitadas e motivadas para levar o termo em propósito (SANTOS, 1998, p. 40).

Para atender a realidade das escolas recém-criadas, o governo contava com um quadro improvisado de professores/as. Selecionados entre aqueles que possuíam o nível médio e superior, geralmente vinham de outros estados, como do Pará, do Ceará, dentre outros do Nordeste, atraídos pelos salários vantajosos. Do próprio Amapá foram contratados professores leigos ou detentores de certificados de conclusão de curso normal (antigo Magistério), obtidos na capital paraense, pois a primeira escola normal do Amapá só veio a funcionar em 1949.

O quadro caótico referente à má qualificação do/a professor/a perdurou por muitos anos, mesmo com programas de formação denominados exame de suficiência oferecido aos professores, que não possuíam qualificação para atuarem em turmas de ensino fundamental do segundo seguimento, esses cursos eram ofertados pela Universidade Federal do Pará (UFPA) com a anuência do Conselho Nacional de Educação (CNE), ainda assim o quadro de docentes era precário (NASCIMENTO, 2008).

\section{A política de formação continuada no estado do Amapá nos últimos quinze anos}

Para que possamos conhecer de forma ampla as Políticas de Formação Continuada para professores/as no Estado do Amapá, faremos uma análise das políticas e programas de formação para professores/as ofertados pela rede estadual em parceria com a Universidade Federal do Amapá (UNIFAP) e instituições privadas nos últimos quinze (15) anos.

A partir da metade da década de 1990, por força da legislação educacional, o Governo Estadual do Amapá traça em conjunto com a UNIFAP, um plano com a finalidade de qualificar os/as professores/as que não possuíam habilitação específica para exercer suas atividades da docência no ensino fundamental em diversas áreas do conhecimento. O Curso de Suficiência foi ofertado em julho de 1997. 
Mesmo com toda a preocupação em qualificar os docentes, o número de professores/as que atuavam em turmas de ensino fundamental e médio e que continuavam sem a devida habilitação era bem significativos. Então, considerando os artigos 61, inciso I, artigo 62, parágrafo $1^{\circ}$ e $4^{\circ}$ e o artigo 63, incisos II e III da Lei de Diretrizes e Bases da Educação Nacional (LDBEN) $n^{\circ}$ 9.394/1996, a UNIFAP, firmou um convênio com o Governo do Estado do Amapá e as prefeituras de Laranjal do Jarí, Serra do Navio, Amapá, Calçoene, Pracuúba, Afuá, Ferreira Gomes e Porto Grande no ano de 2000, com o objetivo de qualificar o corpo docente pertencente aos seus quadros de pessoal e melhorar a qualidade do ensino no estado e municípios. A UNIFAP atendeu mais de dois mil duzentos e noventa e dois (12.292) acadêmicos/as e/ou professores/as no ano de 2.000, como demostram os quadros abaixo conforme os relatórios de gestão da UNIFAP no período de 2000 a 2001.

Quadro1: Processo seletivo especial Secretaria de Estado de Educação do Amapá (SEED)

\begin{tabular}{|l|l|l|l|l|}
\hline Curso & $\mathrm{N}^{\mathrm{o}}$ de Vagas & $\mathrm{N}^{\mathrm{o}}$ de Inscritos & $\begin{array}{l}\text { Relação } \\
\text { Candidato/Vagas }\end{array}$ & $\begin{array}{l}\text { Vagas } \\
\text { Preenchidas }\end{array}$ \\
\hline Pedagogia & 2.500 & 2.826 & 1,13 & 1.880 \\
\hline
\end{tabular}

Fonte: DAVES/UNIFAP

Quadro 2: Processo seletivo especial municípios do Amapá/Calçoene/Pracuúba

\begin{tabular}{|l|l|l|l|l|}
\hline Curso & $N^{o}$ de Vagas & $N^{\text {o de Inscritos }}$ & $\begin{array}{l}\text { Relação } \\
\text { Candidato/Vagas }\end{array}$ & $\begin{array}{l}\text { Vagas } \\
\text { Preenchidas }\end{array}$ \\
\hline Pedagogia & 310 & 310 & 1,00 & 206 \\
\hline
\end{tabular}

Fonte: DAVES/UNIFAP 
Quadro 3: Processo seletivo especial municípios de Ferreira Gomes/Porto Grande/Serra do Navio

\begin{tabular}{|l|l|l|l|l|}
\hline Curso & $\mathrm{N}^{\mathrm{o}}$ de Vagas & $\mathrm{N}^{\mathrm{o}}$ de Inscritos & $\begin{array}{l}\text { Relação } \\
\text { Candidato/Vagas }\end{array}$ & $\begin{array}{l}\text { Vagas } \\
\text { Preenchidas }\end{array}$ \\
\hline Pedagogia & 115 & 124 & 1,08 & 81 \\
\hline História & 50 & 50 & 1,00 & 29 \\
\hline Total & 165 & 174 & 1,05 & 110 \\
\hline
\end{tabular}

Fonte: DAVES/UNIFAP

Quadro 4: Processo seletivo especial município de Afuá, estado do Pará

\begin{tabular}{|l|l|l|l|l|}
\hline Curso & $\mathrm{N}^{\mathrm{o}}$ de Vagas & $\mathrm{N}^{\mathrm{o}}$ de Inscritos & $\begin{array}{l}\text { Relação } \\
\text { Candidato/Vagas }\end{array}$ & $\begin{array}{l}\text { Vagas } \\
\text { Preenchidas }\end{array}$ \\
\hline Pedagogia & 200 & 220 & 1,10 & 192 \\
\hline
\end{tabular}

Fonte: DAVES/UNIFAP

Conforme o quadro acima se percebe um número significativo de professores qualificados no período de 2000 a 2001, cumprindo a exigência legal e melhorando a qualidade de ensino e aprendizagem das crianças, jovens, adolescentes e adultos no Estado do Amapá.

Como se observa, a preocupação primeira do governo era a formação inicial superior do/a professor/a, pois a carência desses profissionais interferia na qualidade de ensino. Mas a LDBEN exigia também dos gestores, um olhar para a formação continuada dos profissionais da educação. Neste sentido, o governo da época cria o Centro de Formação e Desenvolvimento de Recursos Humanos em 23 de dezembro de 1996, para coordenar e executar a política de formação e desenvolvimento dos servidores do Estado. No entanto, não se tem registro de nenhuma ação deste órgão voltado para a qualificação de professores/as no que concerne a programa de pós-graduação.

No ano de 2004, o Centro de Formação e Desenvolvimento de Recursos Humanos passa por mudanças e passa a se chamar Escola de Administração Pública do Amapá (EAP) através da Lei $\mathrm{n}^{\circ} 0811$ de 20 de fevereiro de 2004 e regulamentada pelo Decreto no 0998 de 01 de fevereiro de 2005 e possui status de autarquia do Governo do Estado do Amapá. 
Com a mudança de Centro para Escola, as atribuições foram redefinidas e nos novos programas, projetos e ações voltados para a formação, desenvolvimento e valorização dos servidores foram redefinidas. A instituição atende todos os servidores do Estado e abrange todas as áreas do conhecimento, no entanto iremos centrar as análises na oferta de cursos de formação continuada para professores/as da rede pública de ensino.

As iniciativas de formação de professores/as passaram a ser pauta de discussões na agenda do governo a partir do ano 2000, devido às reivindicações do Sindicato dos Servidores Públicos em Educação no Amapá (SINSEPEAP), bem como devido às cobranças da sociedade em geral por uma educação de qualidade. Na tentativa de cumprir os compromissos com a formação dos/as professores/as amapaenses no ano de 2013, a EAP publicou um edital ofertando cinquenta (50) vagas para o curso de pós-graduação em Docência e Interdisciplinaridade na Educação Básica e Educação de Jovens e Adultos, em parceria com o Instituto Federal do Amapá (IFAP), com carga horária de 360 horas.

Em 2014 a EAP, através da Faculdade Apoena, qualificou mais quatrocentos e oitenta (480) professores/as da rede estadual de ensino. No total foram dez (10) cursos, a saber: Especialização em Educação Especial e Inclusiva, Especialização em Educação Física Escolar, Especialização em Metodologia da Aprendizagem da Matemática, Especialização em Estatística com Ênfase em Educação, Especialização em Metodologia do Ensino do Meio Ambiente, Especialização em Metodologia do Ensino da Língua a das Literaturas de Expressão Francesa, Especialização em Metodologia do Ensino de Artes, Especialização em Metodologia do Ensino da Língua Portuguesa e Literatura, Especialização em Metodologia do Ensino de Geografia e Especialização em Especialização em Educação Escolar Indígena.

Ressaltamos que o Curso de Especialização em Especialização em Educação Escolar Indígena está em fase final em 2015, pois foi ofertado no período das férias escolares, janeiro e julho devido às especificidades dos cursistas que são professores/as indígenas que moram nas aldeias e o deslocamento nos finais de semana até a capital, torna-se inviável, principalmente por questões financeiras e carência de transporte. 
Considerando ainda as instituições governamentais que atuam em cursos de formação continuada de professores/as, existe um anexo a SEED, o Núcleo de Formação Continuada para professores (NUFOC), órgão composto por um coletivo de dezesseis (16) professores/as, vinculados a Coordenadoria de Recursos Humanos (CRH) da SEED.

O NUFOC surgiu em 2003 por iniciativa de um grupo de professores/as que atuavam no Instituto de Educação do Amapá (IETA), um colégio voltado para a formação de professores em nível de segundo grau, criado na cidade de Macapá em 1949, hoje extinto. O NUFOC passou a existir por direito e ter visibilidade em 2004, após muito diálogo e constantes debates com os/as gestores/as educacionais em busca do reconhecimento institucional.

Após seu reconhecimento, o NUFOC passou a atender professores/as de toda a rede, incluindo todos os municípios através de um projeto denominado "Educação semeando vida e cuidando da comunidade: religando o conhecer ao viver com vida". As atividades do projeto são desenvolvidas através de oficinas pedagógicas e as ações são mantidas com recursos dos próprios professores/as, pois a SEED não disponibiliza nenhuma verba para a execução das atividades.

Ao longo dos últimos anos, o NUFOC já realizou oficinas de avaliação da aprendizagem, planejamento, relações interpessoais, entre outras atividades. As oficinas tem a duração de um ou mais dias dependendo da necessidade da escola, porém não há certificação. O professor Orivaldo Azevedo, integrante do grupo que compõe o NUFOC, relatou que existem produções organizadas pelos/as professores/as durante as oficinas. Dentre estas, duas revistas e um livro, que ficam guardadas no anonimato, sem publicação por falta de apoio financeiro. No entanto, com todas as dificuldades, o NUFOC está fazendo a educação acontecer através de suas contribuições.

Uma reflexão a ser considerada é que ao longo desse tortuoso caminho pelo qual a educação amapaense vem trilhando, observou-se que tanto a EAP quanto o NUFOC, não provocaram nenhuma discussão sobre a temática Educação para as Relações Étnico Raciais, muito menos em termos de cursos de pós-graduação. A justificativa é que já foi realizado um curso em 2013 para cem (100) professores/as da rede estadual. Vale ressaltar que hoje 
o Amapá possui um quadro com aproximadamente onze mil (11.000) professores/as distribuídos nos dezesseis (16) municípios do Estado.

No estado do Amapá as discussões sobre Educação para as Relações Étnico-raciais iniciaram tardiamente em 2008, cinco (05) anos após a promulgação da Lei n ${ }^{\circ} 10.639 / 2003$. A temática só passou a ter visibilidade nas escolas estaduais e municipais com a assinatura da Lei Estadual n 1.196 de 14 de março de 2008.

De acordo com dados do Instituto Brasileiro de Geografia e Estatística (IBGE), Censo de 2010, o estado do Amapá possui uma população considerável de negros, fomentar essas discussões é algo primordial. A tabela a seguir nos mostra os dados de autodeclaração nos anos de 2006 a 2010 e o que se observa é um percentual que mesmo com uma expressividade baixa em relação a outras cores, ainda assim, as discussões são necessárias, já que se busca a construção de uma sociedade plural. Vejamos a tabela 1 a seguir:

Tabela 1: População total e respectiva distribuição de percentual no Estado do Amapá, por cor ou raça 2006 - 2010

\begin{tabular}{l|l|l|l|l|l}
\hline \multicolumn{2}{l|}{} & \multicolumn{4}{l}{ População } \\
\hline \multirow{2}{*}{ ANO } & \multirow{2}{*}{$\begin{array}{l}\text { TOTAL } \\
\text { (1000 PESSOAS })\end{array}$} & BRANCA & Potal Distribuição percentual, por cor ou raça (\%) \\
\cline { 3 - 6 } & & & 4.5 & 76,4 & 0,8 \\
& & 21,4 & 6,4 & 70,1 & 0,1 \\
2006 & 596169 & 23,3 & 6,5 & 62,2 & 2,0 \\
2008 & 619 & 27,6 & 8,1 & 74,7 & 0,4 \\
2009 & 641 & 17,6 & 7,6 & 66,9 & 0,3 \\
2010 & 626 & 26,2 & 6,3 & PARDA & \\
\hline
\end{tabular}

Fonte: IBGE, Pesquisa Nacional por Amostra de Domicílios (2005, 2006, 2007, 2008, 2009, 2010).

A tabela acima nos mostra que de acordo com dados estatísticos do IBGE (20062010) em 2006, um percentual de 21,4\% da população do Estado do Amapá era considerado branca. Em 2008 esse número subiu para 27,6\% e em 2010 caiu para 26,2\%. No mesmo ano de 2006 um percentual de 4,5\% da população era negro/a. Em 2008 o índice aumentou para 
8,1\% e em 2010 houve um decréscimo 6,6\%. A cor parda em 2006 foi de 73,4\%, em 2009 74,7\% e 2010, 66,9\%. O índice de percentual de amarelos ou indígenas em 2006 foi de $0,8 \%$, em 2008, 2,0\% e 2010,0,3\%. Com base nestes dados, conclui-se que a maioria da população do Estado do Amapá atualmente é parda (IBGE, 2010, grifos nossos).

Considerando ainda os dados copilados acima, pode-se considerar que a autodeclaração de pessoas pretas no Estado do Amapá, nos anos de 2006 a 2007 aumentou em 44,44\%, de 2007 para 2008. O índice foi estabilizou em 24,61\%, já no período de 2008 a 2009, houve um decréscimo de 9,87\% e de 2009 a 2010 reduziu em 9,58\%. Esses dados foram importantes para a realização de reflexões acerca da identidade do povo amapaense, que é composta por uma parcela significativa de negros/as, mas que não se reconhecem como negros. Munanga (2009, p. 35) afirma que:

\footnotetext{
É através da educação que a herança social de um povo é legada às gerações futuras e inscrita na história. [...] a memória que lhe inculcam não é de seu povo; a história que lhe ensinam é outra; os ancestrais africanos são substituídos por gauleses e francos de cabelos loiros e olhos azuis; os livros estudados lhe falam de um mundo totalmente estranho, da neve e do inverno que nunca viu, da história e da geografia das metrópoles; o mestre e a escola representam um universo muito diferente daquele que sempre a circundou.
}

Os dados ainda nos fazem refletir sobre como estão sendo veiculadas pela escola e mídia, as questões relacionadas ao preconceito no Amapá, pois ele se apresenta de forma velada, como afirma o autor acima se "alimentando o mito brasileiro de estarmos vivendo em um paraíso de coexistência e de aceitação das singularidades" (FERREIRA, 2009, p. 18). Observa-se que é muito comum as negações em relação à cor ou a raça, fato evidenciado através do resultado dos dados do IBGE no ano de 2010.

Para Romanelli (2003), a história da educação brasileira nos mostra que a formação do/a professor/a nunca foi prioridade dos governos, ainda no período colonial, quando os padres jesuítas eram os únicos educadores, nunca se tratou da questão com seriedade. Em 1759 após a expulsão dos padres jesuítas, a Coroa Portuguesa contrata professores leigos, com qualificação deficitária, e péssimos salários, ocasionando uma grande deficiência na educação colonial fato que se estende até os dias atuais. 
Sacristán (2000) enfatiza que o processo de formação do/a professor/a ainda possui amarras, pois as políticas de formação de professores/as são conduzidas através de pacotes prontos e fechadas, aplicadas em diversas realidades, somente para resolver as questões emergenciais. As discussões que o autor discorre acima mostram a importância da formação contínua de professores/as para a efetivação de uma educação com qualidade e que busque a equidade social.

O movimento social negro através de suas organizações pressionou o governo estadual a cuidar da formação continuada dos/as professores/as para atuarem nesta área do conhecimento, este fator vem adquirindo nas últimas décadas, visibilidade principalmente, após a promulgação da Lei n ${ }^{\circ} 10.639 / 2003$.

Em 2012, o estado do Amapá, cria o Conselho Estadual de Promoção da Igualdade Racial (COEPIR) através da Lei $\mathbf{n}^{\mathbf{0}} \mathbf{1 . 7 0 0}$, de 17 de julho de 2012, onde em seu parágrafo $1^{\circ}$ diz que o COEPIR é um órgão de caráter permanente, consultivo e deliberativo, vinculado a Secretaria de Estado da Inclusão e Mobilização Social (SIMS) que tem por finalidade, propor políticas públicas que promovam a igualdade racial no Estado ${ }^{4}$.

No artigo $2^{\circ}$ do COEPIR observam-se os seguintes objetivos: I - combater a prática do racismo; II - combater o preconceito e a discriminação racial; III - reduzir as desigualdades sociais, inclusive no aspecto econômico, financeiro, social, político e cultural, ampliando o processo de controle social sobre as referidas políticas; IV - garantir o fiel cumprimento do Estatuto da Igualdade Racial. Entretanto o COEPIR não contempla a qualificação de professores/as. Vale ressaltar que a Lei $n^{\circ} 10.639 / 2003$, determinada que o poder executivo gerencie a formação docente que atuam em sala de aula, além de estimular o diálogo entre as Instituições de Ensino Superior (IES) para reformularem suas matrizes curriculares.

\footnotetext{
${ }^{4}$ Ver também Resolução no 51/2012-CEE/AP que estabelece normas complementares às diretrizes curriculares nacionais para a educação das relações étnico raciais e para o ensino de história e cultura afrobrasileira, africana e indígena no currículo da educação básica e superior do sistema estadual de ensino do Estado do Amapá e revoga a Resolução nº 075/2009-CEE/AP.
} 


\title{
Curso de especialização em ensino de história e da cultura afro-brasileira
}

Em 2013 na tentativa de atender as ações previstas na legislação federal e estadual, o Governo do Estado do Amapá, através do Núcleo de Educação Étnico Racial (NEER) órgão ligado a SEED firmou um acordo com a Faculdade Atual para a realização de um curso de pós-graduação para docentes da rede estadual de ensino que atuam na capital do Estado e no campo. O curso teve como objetivos:

\begin{abstract}
Capacitar profissionais para a desconstrução do imaginário social negativo em relação à população negra, criar situações de aprendizagem que possibilitem reflexão e discussão sobre a diversidade e questões étnico raciais presentes no país, ensinando criticamente sobre os diferentes grupos que compõem a sociedade, possibilitar que os profissionais desenvolvam competências para atuar nas diferentes áreas do conhecimento, compreendendo que a educação tem papel preponderante na formação da diversidade étnica dos cidadãos, sem perder de vista o caráter universal do saber e da dimensão nacional de sua identidade. Assim, garantir o direito à memória e ao conhecimento da História Afrobrasileira, oferecer subsídios teórico-práticos para o ensino da História e da Cultura Afro-brasileira e Africana no contexto escolar além de capacitar professores para a organização curricular, elaboração de material didático e para as práticas educativas que envolvam os conteúdos de História e da Cultura Afrobrasileira e Africana (NEER, 2012, p. 2).
\end{abstract}

A realização do curso atendeu as exigências da Proposta de Plano Nacional de Implantação das Diretrizes Curriculares Nacionais da Educação das Relações Étnico Raciais e para o Ensino da História e Cultura Afro-Brasileira e Africana, conforme Lei $\mathrm{n}^{\circ}$ $10.639 / 2003$.

Participaram do curso cem (100) professores/as do quadro efetivo da rede estadual de ensino, com uma carga horária de 360 horas divididas em doze (12) módulos com carga horária de trinta horas de 30 horas cada módulo como se observa: História e Cultura AfroBrasileira, História da África I, História da África II, Escravidão e Identidade Africana na Amazônia/ Presença Negra no Amapá, Religiosidade Africana e Afro-Brasileira, Raça, Gênero e Sexualidade Africana, Estado, Sociedade Civil e Questão Étnico racial no Brasil - O Movimento Negro, Literatura Oralidade Africana, História, Pluralidade Cultural e Parâmetros Curriculares Nacionais, Oficina: História e Cultura Africana e Afro-Brasileira, Oficina de Produção de Material Didático, Metodologia da Pesquisa Educacional. 
Para não comprometer o período letivo, as disciplinas foram ministradas nas sextasfeiras nos turnos da tarde e noite e aos sábados pela manhã, tarde e noite. O Convênio firmado entre Governo do Estado e Faculdade Atual para a realização do curso foi de R \$ 78.000,00 (Setenta e Oito Mil Reais) divididos em quatro parcelas.

Segundo a Secretária da Secretaria Extraordinária de Políticas Afrodescendentes (SEAFRO) o curso foi custeado pelo Governo do Estado e teve a duração de oito meses. A estimativa eram que $70 \%$ dos professores seriam destinados a lecionar nas vinte e seis (26) escolas quilombolas do Estado. ${ }^{5}$ Para Pereira (2012, p. 8):

\begin{abstract}
A Pós-Graduação é fundamental para o fortalecimento da identidade e história do povo do Amapá. A importância dessa qualificação é fundamental para difundir a cultura afro-brasileira no ensino básico, pois, o negro não se reconhecer desde criança é muito difícil combater o racismo e promover a igualdade racial.
\end{abstract}

O Governador do Estado após o evento em entrevista local ao Jornal do Dia (Pereira, 2012, p. 8), afirmou que "a especialização dos educadores é uma forma de reconhecer e fortalecer a diversidade da cultura brasileira, da qual faz parte a história negra." A partir da fala do governador, percebe-se que o curso deveria contribuir com uma nova postura do/a professor/a, onde este profissional seria desafiado a desconstruir ideias e concepções já formadas sobre a cultura africana, refletir sobre suas ações diariamente com o intuito de enxergar, ver, reparar, tudo aquilo que se tornaria invisível na rede escolar ao longo da história do Brasil e amapaense (Pereira, 2012, p. 8-9). Entretanto, na prática, estas questões ainda são bastante complexas, pois a maioria destes profissionais não tem encontrado espaço para discutir questões voltas à educação para as relações raciais.

\title{
Considerações finais
}

Na História do Brasil e na constituição do processo educativo, vivenciamos a ausência da cultura afro-brasileira no currículo escolar, mas sempre se percebeu de forma extraordinária o reconhecimento da cultura dominante, sendo reconhecida por grupos que não a possuem.

\footnotetext{
${ }^{5}$ Cf. Pereira, 2012, p.8.
} 
Essa análise nos mostra que ao longo dos anos, a discriminação racial e a exclusão surgem de forma diferente, com uma nova camuflagem carregada de ideologias que produzem e reproduzem a exclusão escolar e social.

Mas também se apresenta como espaço de confronto em busca de mudanças. Ela é dos principais mecanismos de transformação de uma população, sendo papel da mesma estimular a promoção do ser humano em sua integralidade na formação de valores, hábitos e comportamentos que respeitem as diferenças e as especificidades dos grupos. Neste sentido, a promulgação da Lei $\mathrm{n}^{\circ} 10.639 / 2003$, nos leva a refletir sobre questões fundamentais que definem a organização e efetivação do trabalho na escola, pois é sabido que o/a professor/a precisa ter clareza de qual indivíduo pretende formar e para qual sociedade, contudo, acredita-se que a corrente teórica adotada por ele na sua prática tornase fundamental.

Neste artigo, procuramos refletir sobre a formação de professores/as e a educação para as relações étnico raciais na educação básica no Amapá, como mecanismo de implementação a lei em pauta. Mesmo percebendo as lacunas, bem como os obstáculos no currículo escolar, no que diz respeito aos conteúdos de matrizes africanas, ainda assim acreditamos que é possível uma educação fundamentada no respeito à diversidade, na autonomia pedagógica, na construção de valores e na tentativa de construir caminhos que nos levem a reflexão do diferente sem esquecer das suas singularidades. 


\section{Referências}

BRASIL. Lei n. ${ }^{\circ}$ 9.394, de 20 de dezembro de 1996. Estabelece as diretrizes e bases da educação nacional. Disponível

em: <http://www.planalto.gov.br/ccivil_03/Leis/L9394.htm>. Acesso em: 09 jun. 2017.

BRASIL. Lei $n^{\circ}$ 11.645, de 10 de março de 2008. Altera a Lei $n^{\circ} 9.394$, de 20 de dezembro de 1996, modificada pela Lei no 10.639 , de 09 de janeiro de 2003, que estabelece as diretrizes e bases da educação nacional, para incluir no currículo oficial da rede de ensino a obrigatoriedade da temática "História e Cultura Afro-Brasileira e Indígena". Disponível em: <http://www.planalto.gov.br/ccivil03/ato2007-2010/2008/lei/111645.htm>. Acesso em: 18 out. 2017.

BRASIL. Lei $\mathrm{n}^{\circ} \mathbf{1 . 1 9 6}$ de 19 de fevereiro de 2008. Institui a obrigatoriedade do ensino de História e Cultura Afro-brasileira e Africana no currículo da Educação Básica e dá outras providências. Publicada no Diário Oficial do Estado do Amapá n. 4210 de 14 de março de 2008. Autor Deputado Camilo Capiberibe.

BRASIL. Lei no 1.700, de 17 de julho de 2012. Cria o Conselho Estadual de Promoção da Igualdade Racial, e dá outras providências. Disponível em: http://www.al.ap.gov.br/ver_texto_lei.php?iddocumento=38014>. Acesso em: 25 abr. 2017.

BRASIL. Lei $\mathbf{n}^{\mathbf{0}}$ 10.639, de 09 de janeiro de 2003. Instituiu a obrigatoriedade do ensino de História e Cultura Afro-brasileira e Africana no Currículo da Educação Básica. Disponível em: <http://www.planalto.gov.br/ccivil03/Leis/2003/L10.639.htm>. Acesso em: 18 out. 2017.

BRASIL. Resolução no. 51/2012-CEE/AP. Estabelece normas complementares às diretrizes curriculares nacionais para a educação das relações étnico raciais e para o ensino de história e cultura afro-brasileira, africana e indígena no currículo da educação básica e superior do sistema estadual de ensino do Estado do Amapá e revoga a Resolução $\mathrm{n}^{\circ}$ 075/2009-CEE/AP.

Disponível

em:

http://www.gestor.ap.gov.br/editor/Arquivos/Texto/Gestorc284812d6ff5a82fd63e0376c00 4a778Texto.pdf>. Acesso em: 25 abr. 2017.

CONFERÊNCIA MUNDIAL DE EDUCAÇÃO PARA TODOS. Declaração Mundial de Educação para Todos. Plano de Ação para Satisfazer as Necessidades Básicas de Aprendizagem. Brasília, DF: UNIFEC, 1990.

DEL PINO, M. Política educacional, emprego e exclusão social. In: GENTILI, P; FRIGOTTO, G. A Cidadania Negada: política de exclusão na educação e no trabalho: Cortez, 2002.

GARCIA, O. G. Refletindo sobre a aula: descobrindo um caminho para a formação do educador da escola pública. 1995. 282 f. Dissertação (Mestrado em Educação) - Pontifícia Universidade Católica de São Paulo, São Paulo, 1995.

GENTILI, P. Neoliberalismo e educação: Manual do usuário. In: SILVA, T. T.; GENTILI, P. (Org.). Escola S.A: quem ganha e quem perde no mercado educacional do neoliberalismo. Brasília: CNTE, 1996. 
GOMES N. L.; SILVA P. B. G. (Orgs.). O Desafio da Diversidade. In: Experiências étnico-culturais para a formação de professores. 3. ed., Belo Horizonte: Autêntica, 2011. (Coleção Cultura Negra e Identidade)

GOVERNO DO ESTADO DO AMAPÁ. Escola de Administração Pública do Estado do Amapá $(E A P)$. Cursos de Formação de Professores. Disponível em: http://www.eap.ap.gov.br/>. Acesso em: 25 abr. 2015.

INSTITUTO BRASILEIRO DE GEOGRAFIA E ESTATÍSTICA (IBGE). Censo da populacional negra de 2010.2 Disponível em: http://www.ibge.gov.br/home/estatistica/populacao/default_censo_2000.shtm>. Acesso em: 25 abr. 2017.

LOBATO, S. S. Educação na Fronteira da Modernização: a política educacional no Amapá. (1944-1956). Belém: Paca-Tatu, 2009.

MUNANGA, K. Rediscutindo a Mestiçagem no Brasil: identidade nacional versus identidade negra. Belo Horizonte: Autêntica, 2009.

NASCIMENTO, S. S. F. Representações Sociais de Professores sobre Formação Continuada em Educação Especial. 2008, 170f. Dissertação (Mestrado em Educação) Universidade Estácio de Sá, 2008. Disponível em: <http://www.estacio.br/mestrado/educacao/dissertacoes/Dissert_RSPE_simone_do_socorr o.pdf>. Acesso em: 23 jun. 2015.

NOVOA, A. Profissão Professor. Portugal: Porto Editora, 1991.

PEREIRA, M. Formação Continuada para Professores. Diário do Amapá. Caderno Periódico, 2012.

ROMANELLI, O. O. História da educação no Brasil (1930/1973). Petrópolis, RJ: Vozes, 2003.

SACRISTÁN, J. G. Educação Pública: um Modelo Ameaçado: Manual do usuário. In: SILVA, T.T.; GENTILI, P. (Org.). Escola S.A: quem ganha e quem perde no mercado educacional do neoliberalismo. Brasília: CNTE, 1996.

SACRISTÁN, J. G. O currículo: uma reflexão sobre a prática. Porto Alegre: Art Med, 2000.

SANTOS, F. R. História do Amapá. 4. ed. Macapá- AP: Editora Valcan, 1998.

SECRETARIA DE ESTADO DE EDUCAÇÃO DO AMAPÁ. Núcleo de Formação Continuação (NUFOC). Ações e projetos. Macapá-AP, 2012-2013.

SECRETARIA DE ESTADO DE EDUCAÇÃO DO AMAPÁ. Núcleo Estadual de Educação Étnico Racial (NEER): Relatório de atividades e projetos. Macapá-AP, 2012.

UNIVERSIDADE FEDERAL DO AMAPÁ (UNIFAP). Departamento de Apoio ao Vestibular (DAVES). Relatórios de gestão. Macapá-PA: 2000-2001. 